\title{
Achtergronden bij de Richtlijn feedback in de medische vervolgopleiding
}

\section{Wat is feedback?}

Dat 'feedback' geen eenduidig begrip is, blijkt al wanneer de hoeveelheid aan definities in ogenschouw wordt genomen. Van de Ridder et al. (2008) hebben de verschillende definities samengevat in een recent overzichtsartikel. Zij onderscheiden drie groepen definities die zich respectievelijk focussen op a) alleen informatie, b) reactie en interactie, waarbij de ontvangende partij reageert op de informatie van de feedbackgever of c) een cirkel waarbij eerdere informatie gebruikt wordt om gedrag te veranderen, waarna nieuwe input volgt. Tientallen definities zijn door hen beschreven, uitgaande van deze typologie, variërend van 'elke informatie over iemands gedrag' tot 'informatie over het functioneren van een individu in vergelijking met een standaard of het functioneren van peers' ${ }^{11}$ Andere auteurs definiëren feedback als 'commentaar op iemands functioneren' of als 'informatie gegeven door een bron (bijvoorbeeld supervisor, collega, zelf, boek, ervaring) over aspecten van iemands functioneren of begrip'. ${ }^{7}$

Kortom: er zijn vele manieren om feedback te definiëren. Van belang is dat feedback niet beperkt is tot de formele situaties waarin een supervisor besluit expliciet feedback te geven aan een aios, zoals tijdens een Korte Praktijk Beoordeling (KPB) of tijdens een voortgangsgesprek. Sterker nog, de meeste feedback zit verpakt in de dagelijkse routine van overdrachten, in het voor- en of nabespreken van patiënten en in de contacten met patiënten en collega's.
Feedback kan verschillende doelen dienen. In zijn algemeenheid gaat het erom dat met behulp van feedback het zelfinzicht vergroot wordt. Zo kan feedback inzicht geven in het verschil tussen het huidige en het gewenste niveau van functioneren. Het stelt aios daardoor in staat gericht te werken aan de zaken die verbeterd kunnen worden. ${ }^{12-13}$ Feedback kan aios dus helpen zich te focussen wanneer zij door de bomen het bos niet meer zien. Dit leidt tot vermindering van onzekerheid en van de cognitieve belasting, waardoor aios beter gaan functioneren. ${ }^{12}$ Daarnaast maakt goede feedback duidelijk welke concrete aanpassingen nodig zijn om die verbetering te realiseren.

\section{Positieve en negatieve effecten van feedback}

Lange tijd is er binnen de literatuur over feedback voornamelijk aandacht gegeven aan de positieve effecten van feedback. Kluger en DeNisi verrichtten een metaanalyse naar het effect van feedbackinterventies binnen de psychologische literatuur. ${ }^{13}$ Zij includeerden alleen studies waarin een controlegroep werd gebruikt en er metingen van functioneren werden verricht. Zij berekenden op basis van 131 geïncludeerde studies (gebaseerd op 23.663 observaties) 607 'effect sizes' (dit is een maat die de grootte van een eventuele relatie aangeeft). Opmerkelijk genoeg vonden zij dat er in meer dan 38\% van de gevallen sprake was van een negatief effect van feedback op het functioneren: feedbackontvangers gingen slechter functione- 
ren dan voorheen. Gemiddeld wordt er echter een positief effect van feedback op het functioneren gevonden. ${ }^{7} 13$

Zoals Archer in zijn recente artikel over feedback stelt: feedback moet plaatsvinden in een reeks van feedbackinterventies en niet op zichzelf staan. ${ }^{8}$ Dit wordt bevestigd zowel in een Cochrane review als in een BEME review waarin aangetoond wordt dat het effect groter is bij grotere intensiteit van feedback. ${ }^{9-10}$ In de Cochrane review werd het effect van feedback op het functioneren van medisch specialisten onderzocht. ${ }^{9}$ De auteurs includeerden 118 studies. Weliswaar bleek feedback gemiddeld genomen effectief, maar het effect was gering. De Best Evidence Medical Education (BEME) review die 41 studies over het effect van feedback op artsen includeerde (41\% Randomized Controlled Trials, 24\% cross-overdesign, 17\% single cohort, $17 \%$ ander design), toonde in $70 \%$ van de gevallen een positief effect van feedback aan. Negatieve effecten werden niet expliciet benoemd. ${ }^{10}$

Hoewel de bovengenoemde studies niet specifiek de effectiviteit van feedback in de opleiding tot specialist beschrijven, is het waarschijnlijk dat feedback een positief effect heeft op het functioneren van de aios. Feedback kan echter ook negatief uitpakken. De manier waarop feedback gegeven wordt speelt een cruciale rol bij deze effectiviteit.

\section{Verklaring van effecten van feedback}

Voortbouwend op de resultaten van Kluger en DeNisi ${ }^{13}$ ontwikkelden Hattie en Timperley in een uitgebreide review een model dat verklaart waarom feedback tot positieve of juist tot negatieve effecten leidt (Figuur 1). ${ }^{7}$ Hattie en Timperley gaan ervan uit dat het voornaamste doel van feedback is de discrepantie tussen huidig functioneren en het gewenste functioneren op te heffen. Feedback zou dan antwoord moeten geven op drie vragen:

1. 'Waar ga ik heen (wat is het beoogde einddoel)?' Alleen wanneer er heldere doelen zijn verwoord, kan effectieve feedback worden gegeven. Leerdoelen kunnen op verschillende niveaus worden geformuleerd. Een aios Obstetrie \& Gynaecologie moet bevallingen kunnen begeleiden. Dit leerdoel kan worden opgedeeld in het leren begeleiden van een spontane partus, het kunnen verrichten van een vacuümextractie en het kunnen uitvoeren van een sectio caesarea.

2. 'Hoe gaat het op dit moment?' Een supervisor die een aios observeert bij een vacuümextractie kan beoordelen wat goed gaat en wat een volgende keer beter kan.

3. 'Hoe nu verder (wat wordt het volgende tussendoel)?' Feedback moet vervolgens duidelijk maken waar een aios nu staat ten opzichte van het doel. Is een aios in staat zelfstandig een vacuümextractie uit te voeren? Zo niet, wat moet er verbeteren om dat over een bepaalde tijd wel te kunnen? Als een aios wel in staat is de handelingen uit te voeren in een weinig complexe situatie, hoe gaat de aios dat dan leren in moeilijkere situaties? Leren is een traject waarbij een doel niet op zichzelf staat maar weer leidt tot verdere verdieping, meer zelfstandigheid of tot meer ervaring en routine.

Deze drie vragen kunnen op verschillende niveaus worden benaderd en daarin zit het geheim van effectieve feedback. De vier niveaus zijn: taakniveau, procesniveau, zelfregulatieniveau, persoonsniveau (zie voor voorbeelden Tabel 3). Algemene feedback op persoonsniveau draagt het grootste risico om averechts uit te pakken. 
Doel

Verminderen van het verschil tussen het waargenomen gewenste begrip en of gedrag

Het verschil kan verminderd worden door:

Studenten

- Toegenomen inspanning en inzet van efffectievere strategieën OF

- Verlaten van, onduidelijk maken van, of lager inzetten op doelen

Leraren

- Leveren van voldoende aantrekkelijke en specifieke doelen

- Studenten helpen met effectieve leerstrategieën en feedback

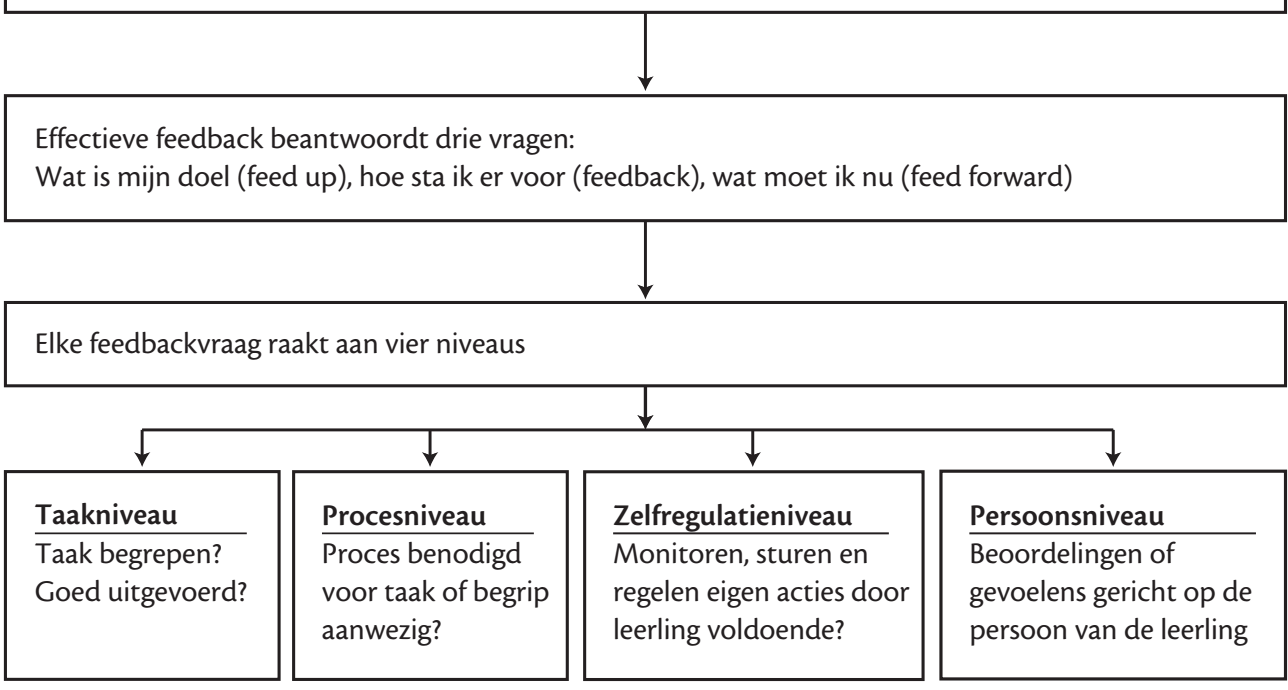

Vertaald uit Hattie en Timperly

Figuur 1. Feedback volgens Hattie en Timperley.

- Taakniveau: Feedback op taakniveau is gericht op de vraag hoe goed een taak is uitgevoerd. Dit type feedback beschrijft concreet welke handelingen ertoe leiden dat een taak tot een goed einde gebracht wordt of juist niet. Dit vereist uiteraard dat de aios al enig inzicht heeft in de taak. Als de taak onbekend is, is het zinvoller instructie en uitleg te geven dan feedback. Daarnaast suggereren meerdere onderzoeken dat specifieke en concrete 'narratieve' feedback (inhoudelijk commentaar) effectiever is dan het geven van cijfers. ${ }^{1-2}$ De informatie 'voldoende' of 'geslaagd' geeft niet aan wat er goed ging en wat beter kan.

- Procesniveau: Feedback op procesniveau richt zich op onderliggende thema's en processen die herkenbaar zijn in het functioneren van een aios. Feedback op dit niveau zou mogelijk leiden tot ‘dieper' leren. 
Tabel 3. Verschillende feedbackniveaus.

\begin{tabular}{|c|c|c|}
\hline Niveau & Omschrijving & $\begin{array}{l}\text { Voorbeeld: een eerstejaars aios heeft moeite om } \\
\text { de overdracht bondig te houden. }\end{array}$ \\
\hline Taak & $\begin{array}{l}\text { Feedback die specifiek } \\
\text { concrete handelingen benoemt } \\
\text { die ertoe leidden dat een taak } \\
\text { tot een goed einde gebracht } \\
\text { is of juist niet. }\end{array}$ & $\begin{array}{l}\text { 'je vertelde bij mevrouw A eerst het lichamelijk } \\
\text { onderzoek en het aanvullend onderzoek, maar } \\
\text { vergat de anamnese; bij meneer B vertelde je alleen } \\
\text { de anamnese en vergat je de rest van het onderzoek. } \\
\text { Probeer bij een volgende overdracht een vaste } \\
\text { structuur aan te houden.' }\end{array}$ \\
\hline Proces & $\begin{array}{l}\text { Feedback die meer algemene, } \\
\text { onderliggende thema's en } \\
\text { processen benoemt die herken- } \\
\text { baar zijn in het functioneren } \\
\text { van een aios. }\end{array}$ & $\begin{array}{l}\text { 'Doordat je veel details in de overdracht opneemt, } \\
\text { krijg ik / krijgen de toehoorders geen goed beeld van } \\
\text { de hoofd- en bijzaken. Probeer te bedenken welke } \\
\text { informatie echt van belang is om over te dragen.' }\end{array}$ \\
\hline Zelfregulatie & $\begin{array}{l}\text { Feedback op de wijze waarop } \\
\text { een aios het gedrag (bij)stuurt } \\
\text { om een gesteld doel te bereiken. }\end{array}$ & $\begin{array}{l}\text { 'Ik kon merken aan de volgorde van je verhaal dat je } \\
\text { geprobeerd hebt meer lijn in de overdracht aan te } \\
\text { brengen. Ik vond het ook goed dat je je supervisor } \\
\text { vooraf geraadpleegd had welke patiënten je wel en } \\
\text { niet zou overdragen'. }\end{array}$ \\
\hline Persoon & $\begin{array}{l}\text { Feedback in de vorm van in } \\
\text { algemene termen gestelde } \\
\text { positieve of negatieve } \\
\text { uitlatingen over de persoon. }\end{array}$ & 'Je bent slordig' of 'je bent traag.' \\
\hline
\end{tabular}

- Zelfregulatieniveau: Zelfregulatie betreft de manieren waarop aios hun gedrag sturen om hun doelen te bereiken. Zelfregulatie wordt beïnvloed door gedrevenheid, gevoel van controle en zelfvertrouwen. Feedback op dit niveau, dus bij voorbeeld op de wijze waarop de aios wel of juist niet eerdere feedback in zijn/haar handelen heeft toegepast, is effectief, onder meer omdat dit weer het feedbackzoekgedrag beïnvloedt. In de paragraaf 'Ontvangen van feedback' wordt hierop verder ingegaan.

- Persoonsniveau: Feedback op dit niveau betreft in algemene termen gestelde positieve of negatieve opmerkingen over de persoon. Deze opmerkingen leiden ertoe dat de aios de aandacht richt op gedachten over zichzelf in plaats van op de taak. Hierdoor kan zijn/haar functioneren hetzelfde blijven of zelfs verslechteren. Overigens zijn prijzende opmerkingen prettig om te horen (en onderzoek toont aan dat mensen het graag willen horen), maar het zorgt er niet voor dat mensen effectiever gaan functioneren.

Concluderend stellen Hattie en Timperley dat het belangrijk is stil te staan bij de doelen van de aios en heel bewust te kiezen voor het niveau waarop feedback gegeven wordt. ${ }^{7}$ Feedback is effectiever wanneer 
deze zich niet richt op de persoon. Wanneer iemand nog nauwelijks kennis of vaardigheden bezit is het verstandiger instructie te geven dan feedback.

\section{Timing van feedback}

Timing en inhoud van feedback moeten idealiter worden aangepast aan de (ingewikkeldheid van de) taak en de ervaring van de leerling. Shute geeft heldere richtlijnen voor de timing van feedback in verschillende situaties. ${ }^{12}$ Grofweg schetst zij met betrekking tot timing twee soorten feedback: directe feedback die meteen na een taak gegeven wordt en uitgestelde feedback die varieert van een paar uur tot weken na een taak. Het is het meest effectief om direct feedback te geven als een taak moeilijk is in relatie tot de vaardigheden van een aios. Wanneer de taak gemakkelijker is, is het effectiever de feedback uit te stellen.

Makkelijk en moeilijk moet hier worden geïnterpreteerd in relatie tot de vaardigheden van de aios: een vaardige aios zal een taak vaker makkelijk vinden. Als een aios bijvoorbeeld pas voor de derde keer een laparoscopische cholecystectomie doet, is het zinvol fouten direct te corrigeren. Is het echter de dertigste keer, dan kan het zinvol zijn de aios zelf eventuele problemen op te laten lossen en achteraf de gekozen strategie te bespreken, mits uiteraard de patiëntveiligheid dit toestaat. Als er bij ervaren aios steeds onderbroken wordt en tips gegeven worden, kan dit er toe leiden dat hij of zij minder goed gaat functioneren omdat men uit de concentratie en het werkpatroon wordt gehaald.

Shute geeft voorts aan dat vaardige aios vooral profiteren van faciliterende feedback, waarbij hints en suggesties worden gegeven zodat de aios zelf een verbeterplan kan opstellen. Minder vaardige aios hebben baat bij directieve feedback waarin helder gesteld wordt wat veranderd moet worden. Samenvattend moet rekening gehouden worden met de moeilijkheid van de taak en met de ervaring van de aios. Meer feedback leidt niet altijd tot een beter functionerende aios. ${ }^{13}$

\section{Ontvangen van feedback}

Veel literatuur geeft informatie over het effectief geven van feedback. De ontvangers van feedback worden hierin neergezet als passieve individuen die nauwelijks van invloed zijn op de uiteindelijke effectiviteit. Recent onderzoek toont aan dat het tegendeel waar is. Mensen gaan zelf vaak actief op zoek naar informatie over hun functioneren en reageren verschillend op exact dezelfde feedback. Kortom, niet alleen de gevers, maar ook de ontvangers spelen een rol in het uiteindelijk effect van feedback.

\section{Feedbackzoekgedrag}

Aios maken bewuste keuzes in wie ze wel of niet om feedback vragen en op welke momenten. Grofweg kunnen twee verschillende vormen van feedbackzoekgedrag worden onderscheiden:

1. Impliciet gedrag (monitoring) waarbij feedbackinformatie wordt verkregen door het observeren van de omgeving en anderen (bijvoorbeeld: een aios belt in de dienst een supervisor en stelt een plan voor; de supervisor gaat akkoord; de aios interpreteert dit als feedback dat de voorstellen voor beleid goed zijn).

2. Expliciet gedrag (inquiry) waarbij feedback wordt verkregen door er direct naar te vragen (bijvoorbeeld: de aios in dit voorbeeld vraagt aan de supervisor of hij/zij het voorgestelde beleid goed vindt).

Teunissen et al. hebben onderzoek gedaan naar factoren die invloed hebben op feedbackzoekgedrag van aios Obstetrie \& Gynaecologie. ${ }^{14}$ Hierbij bleek een aantal factoren van belang. Een eerste factor is de inschatting van de voor- en nadelen van 
het vragen van feedback. Aios die bang zijn voor gezichtsverlies of voor een slechte beoordeling van het functioneren kunnen afzien van het direct vragen naar feedback en zullen eerder impliciet zoekgedrag vertonen. Als een aios bijvoorbeeld een ernstig zieke patiënt per ongeluk ontslagen heeft zal hij/zij minder geneigd zijn direct te vragen om feedback maar uit de reacties op de overdracht afleiden dat het gevoerde beleid niet de gewenste aanpak is. Een tweede factor die het feedbackzoekgedrag beïnvloedt is de algemene doelgerichtheid van aios. Sommige aios zullen prestatiegericht zijn wat inhoudt dat zij een goede prestatie af willen leveren en geloven in het bezit van intelligentie en vaardigheden. Andere aios zijn ontwikkelingsgericht wat impliceert dat zij gericht zijn op hun ontwikkeling en geloven in de ontwikkelbaarheid van intelligentie en vaardigheden. Deze laatste groep zal bij falen zich voornemen een volgende keer harder te werken en het nogmaals te proberen; de eerste groep zal bij falen eerder van mening zijn dat ze het gewoon niet kunnen.

Goede feedback kan ervoor zorgen dat er een verschuiving plaatsvindt van prestatiegericht naar het (meer effectievere) ontwikkelingsgericht zijn. De derde belangrijke factor bij het feedbackzoekgedrag is de stijl van de supervisor. Wanneer supervisoren helder zijn over wat ze verwachten en wat de doelen zijn, zal een aios eerder direct om feedback vragen. Supervisoren kunnen aios dus helpen door te expliciteren wat zij van aios willen.

Kortom, aios zijn geen passieve ontvangers van feedback. Zij zoeken feedback op een impliciete of expliciete manier. De kosten en baten van de feedback, de algemene doelgerichtheid van de aios en, last but not least, de stijl van de supervisor hebben invloed op dit feedbackzoekgedrag.

\section{Literatuur}

1. Crooks TJ. The impact of classroom evaluation on students. Rev Educ Research 1988;5:438-481.

2. Black P, William D. Assessment and classroom learning. Assessm Educ 1998;5(1):7-75.

3. Sargeant J, Mann K. Feedback in medical education: Skills for improving learner performance. In: Cantillon P, Wood D, editors. ABC of Learning and Teaching in Medicine. 2 ed. BMJ Books; 2010; p. 29-32.

4. Giving Feedback. In: Bullock I, Davis M, Lockey A, Mackway-Jones K, editors. Pocket Guide to Teaching for Medical Instructors/ Advanced Life Support Group and Resuscitation Council (UK). 2 ed. Oxford: Blackwell Publishing; 2008; p. 57-68.

5. Pendleton D, Schofield T, Tate P, Havelock P. The new consultation: developing doctor-patient communication. Oxford: Oxford University Press; 2003.

6. Brand PL, Boendermaker PM. [Give feedback: crucial competence in medical education]. Ned Tijdschr Geneeskd 2009;153(6):250-253.

7. Hattie J, Timperley H. The power of feedback. Rev Educ Research 2007;77(1):81-112.

8. Archer JC. State of the science in health professional education: effective feedback. Med Educ 2010;44(1):101-108.

9. Jamtvedt G, Young JM, Kristoffersen DT, O'Brien MA, Oxman AD. Audit and feedback: effects on professional practice and health care outcomes. Cochrane Database Syst Rev 2006;(2):CD000259.

10. Veloski J, Boex JR, Grasberger MJ, Evans A, Wolfson DB. Systematic review of the literature on assessment, feedback and physicians' clinical performance: BEME Guide No. 7. Med Teach 2006;28(2):117-128.

11. Van de Ridder JM, Stokking KM, McGaghie WC, Ten Cate OT. What is feedback in clinical education? Med Educ 2008;42(2):189-197.

12. Shute VJ. Focus on Formative Feedback. Rev Educ Research 2008;78(1):153-189.

13. Kluger AN, DeNisi A. The effects of feedback interventions on performance: a historical review, a meta-analyse, and a preliminary feedback intervention theory. Psychol Bull 1996;(119):254-284.

14. Teunissen PW, Van der Stapel DA, Scherpbier A, Boor K, Scheele F. Who wants feedback? An investigation of the variables influencing residents' feedback-seeking behavior in relation to night shifts. Acad Med 2009;84(7):910-917. 
Achtergronden bij de Richtlijn feedback in de medische vervolgopleiding $\mid$ K. Boor et al.

De auteurs:

Dr. K. Boor is aios Obstetrie \& Gynaecologie, VUmc, Amsterdam.

Dr. P.W. Teunissen is onderzoeker medisch onderwijs, Universiteit van Maastricht en aios Obstetrie \& Gynaecologie, VUmc, Amsterdam.

Prof. dr. P.L.P. Brand is hoogleraar klinisch onderwijs UMCG, en kinderarts, Isala klinieken Zwolle.

\section{Correspondentieadres:}

K. Boor, VU Medisch Centrum, afdeling Obstetrie \& Gynaecologie, postbus 7057, 1007 MB Amsterdam. E-mail: klarkeboor@gmail.com

Belangenconflict: geen gemeld

Financiële ondersteuning: geen gemeld 